\title{
Milligram per Milliliter per Hour
}

National Cancer Institute

\section{Source}

National Cancer Institute. Milligram per Milliliter per Hour. NCI Thesaurus. Code C85711.

Milligrams per milliliter per hour. 